\title{
Role of Urban Management in Spatial Distribution of Green Lands: A Quantitative Survey in Shiraz, Iran
}

\author{
Mehdi Momeni ${ }^{1}$ \\ ${ }^{1}$ Department of Geography \& Urban Planning, Najafabad Branch, Islamic Azad University, Najafabad, Iran \\ Correspondence: Mehdi Momeni, Department of Geography \& Urban Planning, Najafabad Branch, Islamic Azad \\ University, Najafabad, Iran. E-mail: momeni100@gmail.com
}

Received: November 30, 2014

Accepted: December 3, 2014 Online Published: January 22, 2015

doi:10.5539/jsd.v8n1p54

URL: http://dx.doi.org/10.5539/jsd.v8n1p54

\begin{abstract}
Urban planning and management in economic, social, cultural, health and hygienic, and safety and security fields is one of the main concerns of officials and citizens in each country. Nowadays, the necessity of green lands in cities has become very important. Green lands refine the air and reduce air pollutants, strike ecological balance, and absorb piercing sickening sounds. Today, people are exposed to various psychological turmoil and ailments due to modern industrial life. Since one of the criteria for sustainable urban development is paying attention to the equal population distribution, green lands should be managed in such a way that spatial balance is prevailed. Since the city of Shiraz in Iran is located in a semi-arid climatic area, its population has been growing in recent years and efficient management of urban green lands seems vital to address and solve these problems. This study aims to examine the role of urban management in spatial distribution of green lands in a district in the city of Shiraz, Iran. To achieve the aim of the study, a reliable and valid questionnaire was distributed in district 8 in the city of Shiraz. This study is an applied research based on its purpose and analytical- descriptive case study according to its nature. The results of the study show a physical expansion and population increase in this district in recent decades which cause the imbalance between population and green lands and lack of optimal management of green lands in this district. More attention should be paid to sustainable urban development and new plans should be presented for the development and management of green lands.
\end{abstract}

Keywords: green lands, sustainable development, urban management, spatial distribution, Shiraz, Iran

\section{Introduction}

The concept of cities and urban areas without effective green lands in their various forms is no longer conceivable. Impacts and consequences of urban development and the complexity of their environmental problems have made the existence of green lands and their expansion more necessary than before. Cities as the hearts of human concentration, activity and human life have no other choice but adopting a functional structure affected by natural systems in order to guarantee their stability (Almudi, 2008; Azani, 2004). Meanwhile, the green lands as the integral and essential part of urban body has an essential role in the metabolism of cities and its deficiency can lead to serious disorders in urban life (Mehrmand, 2004). The main objective in designing green lands is to achieve its social effects in order to make human and nature further closer together than before (Ahmadi, 2009) although social and psychological yield and efficiency are expected from its environmental functioning (Arianpoor, 2000). Therefore, development, designing, and implementation of green lands should be based on a correct view of urban environmental and social needs, capabilities, and facilities (Imani Jorjami, Bigdeli, and Hanachi, 2002). The two categories of "sustainable development" and "improving productivity" should always be a priority for development policies and creating green lands (Majnoonian, 2000). Green lands management in cities is one of the important subcategories and sections of urban management (Crane \& Kinzig, 2005; Hekmati, 2002). Urban green lands management is part of urban skeleton or morphology. In other words, Green lands along the city's physical structure determine the overall appearance of a city (De Vries \& Goossen, 2002; Ziari, 2006). Hence, if green lands management is done properly and carefully implemented, management logic dictates that there should somehow be a balance between these two factors namely the inanimate and animate sections of the morphology of the city (Poormohammadi, 2003). The management of urban green lands as major part of urban planning has urban environmental skeletal or structural effects and applying principles of environmental science and optimization of urban lands are considered in its optimal implementation to solve 
different problems. These problems can include air pollution, noise, traffic and population increase (Shia, 2003).

Green lands management is part of the management of Shiraz metropolitan city. Proper management of green lands both in private and public sectors of municipality can make an effective contribution to soothing humans, verdancy, and beauty of the city. So this important question arises whether the green land is spatially equally distributed in district 8 in Shiraz.

\section{Literature Review}

The importance and status of green lands in human life and its role in the spiritual or psychological and mental needs of humans is to the extent that makes paying attention to this important issue in urbanization and urban planning essential (Moshkelati, 2004). With the beginning of industrial revolution and the mechanization of life, humans have distanced from nature and have destroyed it consciously or unconsciously. Among theories about the importance of green lands and its application in human life is Camillo Sitte's theory in 1889. Camillo Sitte, the Austrian urban constructor, suggested in his book named Urbanization that the remedy is to go back to the art style of past centuries (Moosa-Kazemi, 2007). The normal growth of medieval towns had attracted the attention of Sitte to itself and he considered it as the tool to get rid of the present defects and disadvantages of modern cities. The rules of urbanization were reduced in one sentence for Sitte and that is cities must guarantee and protect the interests and prosperity of their residents (Gülez \& Demirel, 2004; Shia, 2000).

In the late nineteenth century, one of the solutions proposed for many problems of settlement in cities was the idea of making garden-like cities. This idea was proposed by the English Ebenezer Howard. Howard published his theory in his book; Tomorrow is a peaceful path to real reform, in 1898. He mainly concentrated on getting rid of the harmful aspects of the industrial revolution and the elimination of populated districts. The city proposed by Howard has an area of 2,400 hectares that $1 / 6$ of it is assigned to the population and the rest goes to green lands, forest, and agriculture. In fact, Howard's suggested plan was a link between the urban and rural areas or cities and villages (Jim \& Wendy, 2006; Nik-kar, 2005).

Clarence Stine proposed a plan in which he proposed that the schools area should be about half a mile apart from the boundary of parks. In his proposed plan, creating green lands should adhere to the neighborhood units.

Rodburn proposed a plan for one of suburban areas in New Jersey. In Rodbrn's plan, parks are located in the center of big blocks and were considered as the highest point in the neighborhood district. In this plan, houses are built in groups and parks and green lands are around them. In general, the aim of Rodburn's plan is to create garden-cities in metropolitan cities in communities. In this plan, it is attempted to get people closer to nature so that they gain more comfort and peace. In this plan, green land is of great importance and it aims to develop a healthy urban community (Shia, 2000). Considering the machine era and the needs of urban communities in the post industrial revolution, Lokorbozie offered a plan about building cities in 1922. In this plan, the city center or downtown can bear traffic congestion in the city and much attention is paid to green lands and open space. The city is considered as a business center and should play its roles in congested compressed areas. In this plan, open space is adequately provided due to the need for plenty of fresh air and vertical expansion of the city is very important in some parts. Another urban designer is Wagnner (1918-1841). He belonged to a generation that was very optimistic about industry. Wagner designed a plan for a residential neighborhood in Vienna in order to prevent the disordered messy development of such districts and neighborhoods. In this plan, Wagner provided an open outdoor and relatively large space in the center of the neighborhood which he called the respiration center of the neighborhood. Celerense presented a plan in which the optimum limit or boundary of constructing parks in residual neighborhoods must be of 3 minutes. He believes that 3 minutes is a suitable time for house residents to get to parks and meet their recreational needs (Lane \& Corbett, 2005; Mazini, 2000; Tsaur, Lin \& Lin, 2006).

In urban history and culture in Iran, gardens and green lands have a special place so that it is deduced from the writings of Greek historians that gardens surrounded the houses of most Iranians almost three thousand years ago (Momeni, 2007) and the word paradise was used to refer to the gardens surrounding the house (Saeeidnia, 2003).

Nowadays, as experts believe, planning and designing urban green lands are impossible regardless of the problems, criteria, and optimal standards of urban improvements, development and designing (Leghaee, 2000; Malone \& Yohe, 2002). In other words, planning or designing urban green lands is one of the main interferences involved in urban life and urban system which is organized based on recognizing, and analyzing urban society's needs in one hand and facilities, limitations, and environmental needs on the other hand. Therefore, the related criteria and standards are of great importance (Keshtkar, 2002; Rosa, Eduardo \& Erin, 2002).

According to studies by the Department of Housing and Urban Development, the reasonable and acceptable share or portion for urban green lands in cities is 7-12 square meters in cities in Iran which is less than the index 
determined by the United Nations Environment which is 25-50 square meters per person. However, in different cities of the country, this figure differs according to their different geographical and climatic characteristics, the amount of which is determined by approved plans in each city (Consulting Engineers, 2004). The concept of green land portion per person can only be used for green lands provided for spending leisure time, playing and recreation (Bahram Soltani, 2005; Tissot, 2005).

\section{Research Questions}

The following research questions were posed in this study:

- Is there a significant relationship between spatial distribution of green lands and ecological issues in district 8 in the city of Shiraz.

- Is there a significant relationship between urban management and spatial distribution of green lands?

- To what extent are the actions taken in the studied district in compliance with the criteria of urban green lands management?

\section{Hypotheses}

In parallel with the above research questions, the following hypotheses were constructed:

- There is a significant relationship between spatial distribution of green lands and ecological issues in district 8 in the city of Shiraz.

- There is a significant relationship between urban management and spatial distribution of green lands.

\section{Materials and Methods}

The design of this study is a survey questionnaire. The research method is analytical-descriptive in nature and applied-developmental based on its purpose. The statistical population is the population in district 8 in the city of Shiraz which based on its residents in the neighborhoods of the district was estimated to be about 5740 people. The data was gathered based on the field studies and documents. Random sampling was used so that estimating the sample size was done using Cochrane approach (Hafeznia, 2006).

$$
n=\frac{t^{2} p q / d^{2}}{1+\frac{1}{N}\left(\frac{t^{2} p q}{d^{2}}-1\right)}
$$

The first draft of the questionnaire was developed considering the issues pointed in the literature. Then, the first draft of the questionnaire was sent to two experts to be reviewed in order to ensure the content validity of the questionnaire (Mizutani, 2009; Huck, 2004). Based on the experts' suggestions, the first draft of the questionnaire was revised and the necessary changes were made in the second draft. Then, the second draft of the questionnaire was piloted. The act of piloting ensures that questionnaire items are interpreted as much as possible in the same way by every survey respondent. Cronbach's alpha coefficient was calculated for the questionnaire items to test the internal consistency of the items measuring the same construct (Huck, 2004). The Cronbach's alpha coefficient was found to be 0.9 for the whole questionnaire. Although the obtained coefficients indicated a good internal reliability for the questionnaire, some items were deleted to increase the reliability and internal consistency of the questionnaire. Some minor changes in the wording of the items were also made considering the problems encountered during the pilot study. Figure 1 illustrates the stages of the questionnaire design and validation procedures. 


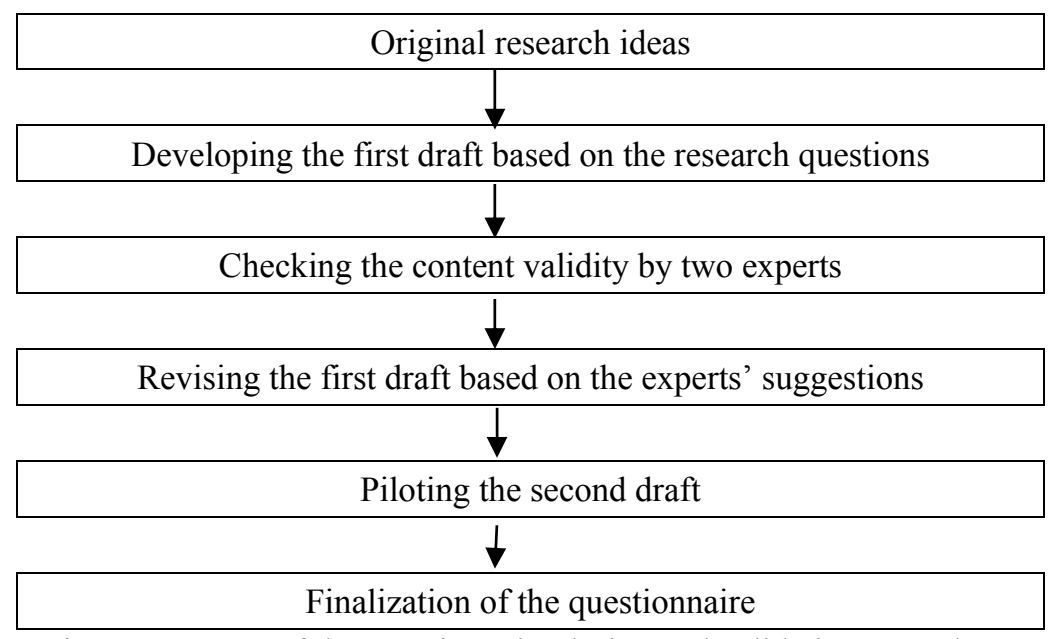

Figure 1. Stages of the questionnaire design and validation procedures

In total, the validated and reliable questionnaire was distributed among 300 respondents in district 8 in the city of Shiraz. Then, the questionnaires were collected and analyzed using Excel and SPSS softwares.

\section{Research Results}

The questionnaire is researcher-made consisting of 4 general questions, 14 closed technical questions, and 4 open technical questions. General questions are about: gender, age, education, and occupation. Based on the findings of the research, there were $46 / 4 \%$ male and $53 / 6 \%$ female respondents (Table 1 ).

Table 1. Distribution of the frequency of respondents based on gender

\begin{tabular}{cccccc}
\hline \multicolumn{2}{c}{ Indexes } & Frequency & Percentage & Value in Percentage & Accumulative Frequency \\
\hline \multirow{4}{*}{ Valid } & Female & 161 & $53 / 6$ & $52 / 4$ & $52 / 4$ \\
& Male & 139 & $46 / 4$ & $47 / 6$ & $100 / 0$ \\
& Total & 300 & $100 / 0$ & $100 / 0$ & \\
\hline
\end{tabular}

In terms of age, respondents under 15 years old were $13 / 6 \%$, those between 15 and 30 years old were $31 / 6 \%$, those between 30 and 45 years old were $29 / 6 \%$, those between 45 and 60 years old were $22 / 3 \%$, and those who were over 60 were $2 / 6 \%$ (Table 2 ).

Table 2. The distribution of age frequency of respondents

\begin{tabular}{cccccc}
\hline & Indexes & Frequency & Percentage & $\begin{array}{c}\text { Value in } \\
\text { Percentage }\end{array}$ & $\begin{array}{c}\text { Accumulative } \\
\text { Frequency }\end{array}$ \\
\hline \multirow{4}{*}{ Valid } & Less than 15 & 41 & $13 / 6$ & $13 / 8$ & $13 / 8$ \\
& Between 15 and 30 & 95 & $31 / 6$ & $30 / 9$ & $44 / 7$ \\
& Between 30 and 45 & 89 & $29 / 6$ & $30 / 2$ & $74 / 9$ \\
& Between 45 and 60 & 67 & $22 / 3$ & $22 / 4$ & $97 / 3$ \\
& Over 60 & 8 & $2 / 6$ & $2 / 7$ & $100 / 0$ \\
\hline
\end{tabular}

Based on the results of the research, in the statistical sample, $3 / 3 \%$ of the respondents were illiterate, $27 / 6 \%$ of the respondents' education was below diploma, $33 / 6 \%$ were above diploma, $32 \%$ were undergraduate, and $3 / 3 \%$ were graduate (Table 3). 
Table 3. Distribution of the frequency of respondents' educational status

\begin{tabular}{cccccc}
\hline Indexes & Frequency & Percentage & $\begin{array}{c}\text { Value in } \\
\text { Percentage }\end{array}$ & $\begin{array}{c}\text { Accumulative } \\
\text { Frequency }\end{array}$ \\
\hline \multirow{4}{*}{ Valid } & Illiterate & 10 & $3 / 3$ & $3 / 4$ & $3 / 4$ \\
& Below diploma & 83 & $27 / 6$ & $26 / 3$ & $29 / 7$ \\
& Diploma and above & 101 & $33 / 6$ & $34 / 4$ & $64 / 1$ \\
diploma & & & $32 / 5$ & $96 / 6$ \\
& D Undergraduate & 96 & 32 & $3 / 4$ & $100 / 0$ \\
Graduate & 10 & $3 / 3$ & $100 / 0$ & \\
\hline
\end{tabular}

Regarding respondents' job based on the results of the research, in the statistical sample, $17 / 6 \%$ of the respondents were homemakers, $26 \%$ were employees, $21 / 7 \%$ were self-employed, $25 \%$ were students, and others were $9 / 7 \%$ (Table 4 ).

Table 4. Distribution of the frequency of employment status

\begin{tabular}{cccccc}
\hline & Indexes & Frequency & Percentage & Value in Percentage & Accumulative Frequency \\
\hline \multirow{4}{*}{ Valid } & Homemaker & 53 & $17 / 6$ & $17 / 9$ & $17 / 9$ \\
& Employee & 78 & 26 & $25 / 4$ & $43 / 3$ \\
& Self-employed & 65 & $21 / 7$ & 22 & $65 / 3$ \\
& Student & 75 & 25 & $24 / 7$ & 90 \\
& Others & 29 & $9 / 7$ & 10 & $100 / 0$ \\
& Total & 300 & $100 / 0$ & $100 / 0$ & \\
\hline
\end{tabular}

Regarding technical questions and the level of using green lands, $62 \%$ of the respondents selected the options "very much", and "much" (Table 5).

Table 5. The level of using green lands in the city

\begin{tabular}{cccccc}
\hline \multicolumn{1}{c}{ Indexes } & Frequency & Percentage & Value in Percentage & Accumulative Frequency \\
\hline \multirow{4}{*}{ Valid } & Very much & 68 & $22 / 6$ & $22 / 8$ & $22 / 8$ \\
& Much & 118 & $39 / 4$ & $38 / 7$ & $61 / 5$ \\
& Moderate & 102 & 34 & $34 / 2$ & $95 / 7$ \\
& Little & 10 & $3 / 3$ & $3 / 5$ & $99 / 2$ \\
& Never & 2 & $0 / 7$ & $0 / 8$ & $100 / 0$ \\
& Total & 300 & $100 / 0$ & $100 / 0$ & \\
\hline
\end{tabular}

Regarding the effect of green lands on the mood and spirits of the respondents, based on the findings $31 / 4 \%$ of the respondents selected the option "Very much", 39\% selected "Much", 25\% selected "Moderate", 3/3\% selected "Little", and 1/3\% selected the option "No effect" (Table 6). 
Table 6. The effect of green lands on the mood and spirits of the respondents

\begin{tabular}{cccccc}
\hline \multicolumn{1}{c}{ Indexes } & Frequency & Percentage & Value in Percentage & Accumulative Frequency \\
\hline \multirow{4}{*}{ Valid } & Very much & 94 & $31 / 4$ & $31 / 6$ & $31 / 6$ \\
& Much & 117 & 39 & $38 / 5$ & $70 / 1$ \\
& Moderate & 75 & 25 & $25 / 1$ & $95 / 2$ \\
& Little & 10 & $3 / 3$ & $3 / 4$ & $98 / 6$ \\
& No effect & 4 & $1 / 3$ & $1 / 4$ & $100 / 0$ \\
& Total & 300 & $100 / 0$ & $100 / 0$ & \\
\hline
\end{tabular}

Regarding the level of children's happiness and safety in using green lands, based on the findings, $40 \%$ of the respondents selected the option "Very much" and "Much" (Table 7, and Figure 2).

Table 7. Children's happiness and safety in using green lands

\begin{tabular}{cccccc}
\hline & Indexes & Frequency & Percentage & Value in Percentage & Accumulative Frequency \\
\hline \multirow{4}{*}{ Valid } & Very much & 48 & 16 & $16 / 3$ & $16 / 3$ \\
& Much & 72 & 24 & $23 / 3$ & $39 / 6$ \\
& Moderate & 90 & 30 & $30 / 2$ & $69 / 8$ \\
& Little & 68 & $22 / 6$ & $22 / 6$ & $92 / 4$ \\
& No effect & 22 & $7 / 4$ & $7 / 6$ & $100 / 0$ \\
& Total & 300 & $100 / 0$ & $100 / 0$ & \\
\hline
\end{tabular}

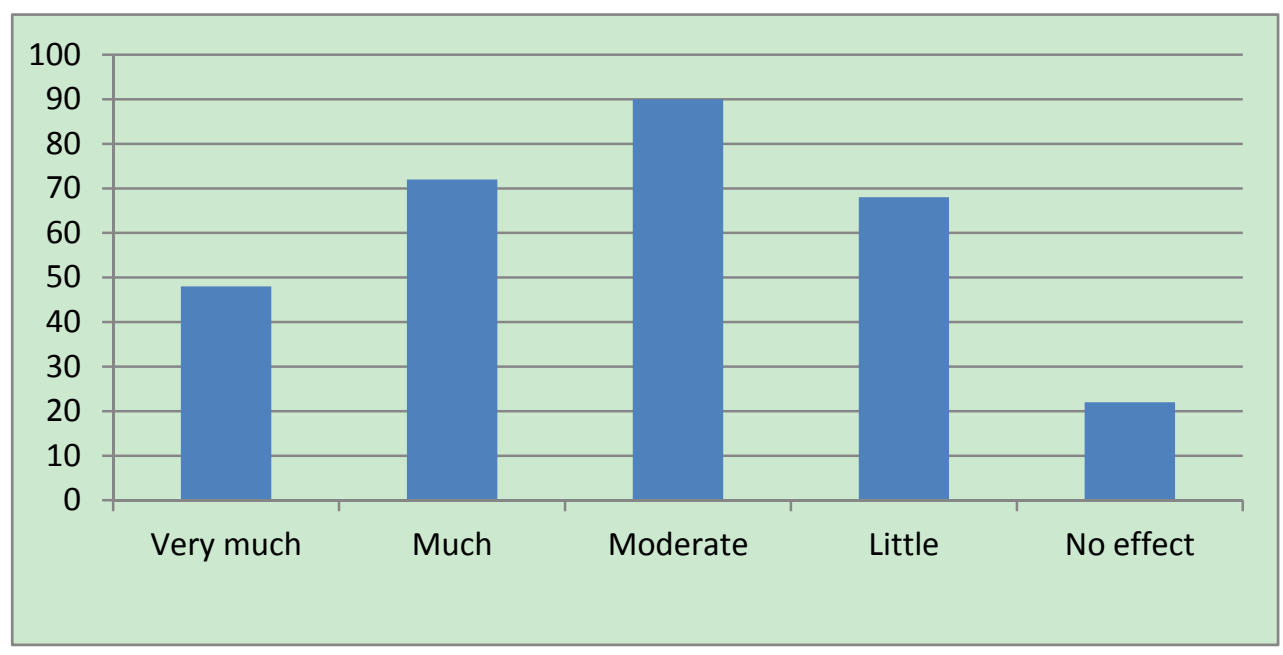

Figure 2. Children's happiness and safety in using green lands

Regarding the pleasure of using green lands with family or friends, based on the findings, $88 / 3 \%$ of the respondents selected the option "Very much" and "Much" (Table 8, and Figure 3). 
Table 8 . The level of enjoying using green lands with family or friends

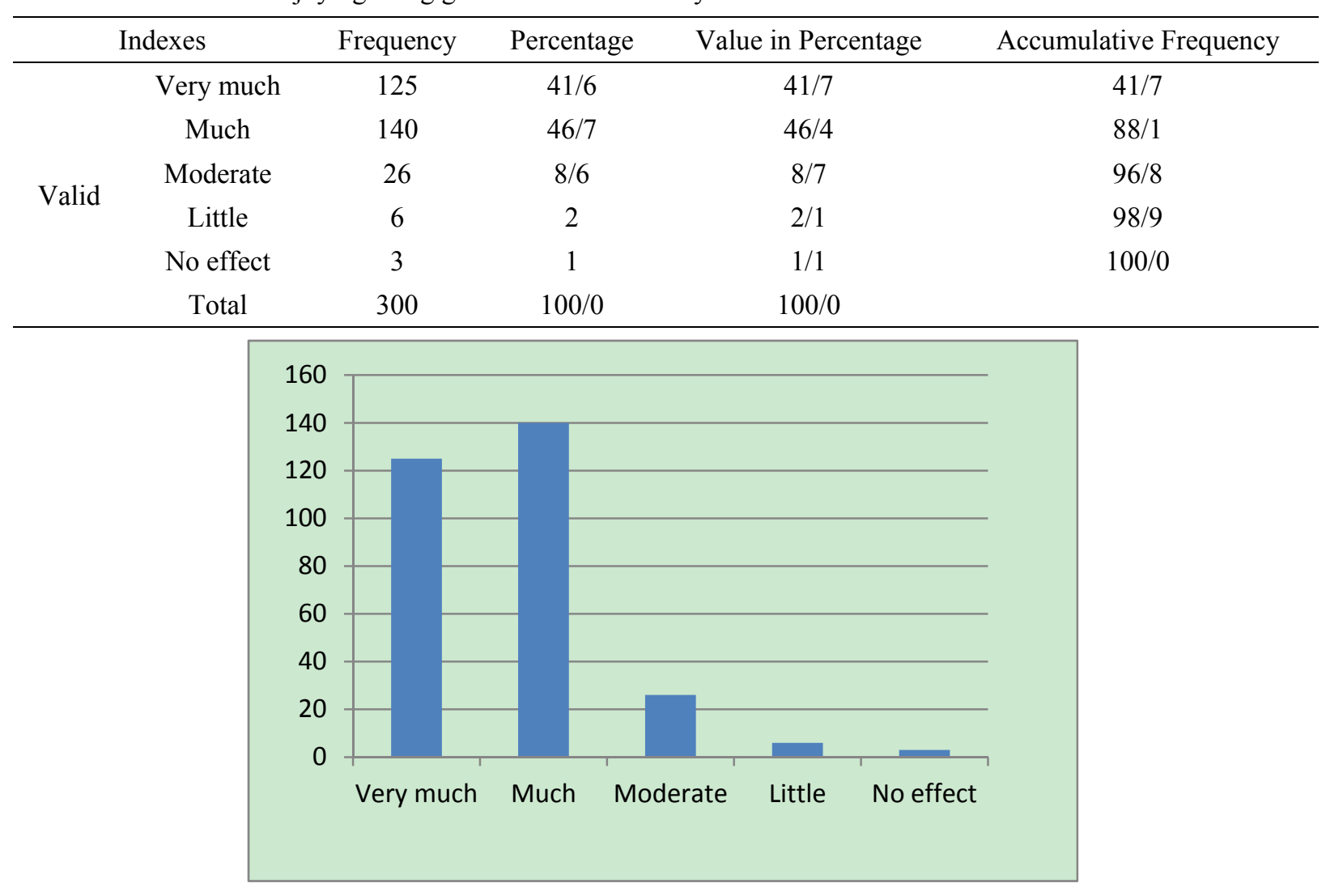

Figure 3. The level of enjoying using green lands with family or friends

Regarding the suitability of green lands in region 8 in Shiraz, according to each district and its population, 43/7\% of the respondents selected the option "Little", 6/3\% selected the option "No effect" (Table 9, and Figure 4).

Table 9. The level of the appropriateness of urban green lands in relation to each district and population density in region 8 in Shiraz

\begin{tabular}{cccccc}
\hline Indexes & Frequency & Percentage & Value in Percentage & Accumulative Frequency \\
\hline \multirow{4}{*}{ Valid } & Very much & 3 & 1 & $1 / 2$ & $1 / 2$ \\
& Much & 80 & $26 / 6$ & 27 & $28 / 2$ \\
& Moderate & 67 & $22 / 4$ & $22 / 5$ & $50 / 7$ \\
& Little & 131 & $43 / 7$ & $42 / 8$ & $93 / 5$ \\
& No effect & 19 & $6 / 3$ & $6 / 5$ & $100 / 0$ \\
& Total & 300 & $100 / 0$ & $100 / 0$ & \\
\hline
\end{tabular}




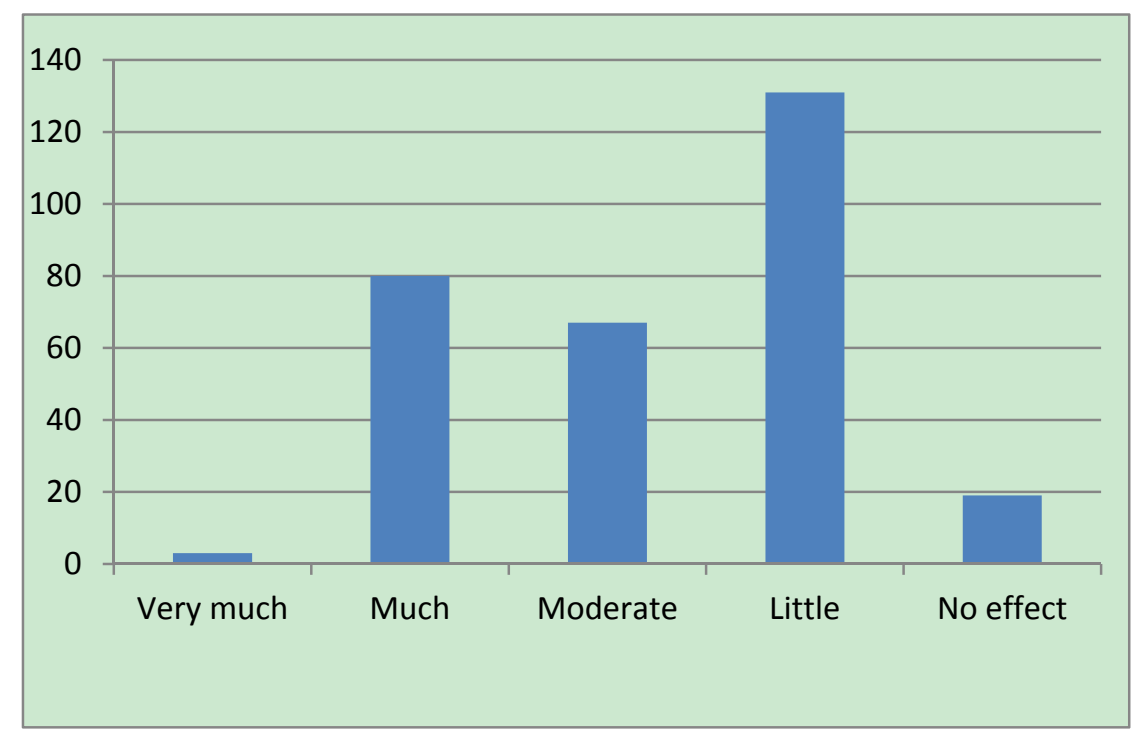

Figure 4. The level of the appropriateness of urban green lands in relation to each district and population density in region 8 in Shiraz

Regarding the effect of green lands on reducing pollution in the city, according to the findings, $2 / 3 \%$ of the respondents selected the option "Very much", 6\% selected the option "Much", 32/7\% "Moderate", 35\% "little", and $24 \%$ "No effect" (Table 10, and Figure 5).

Table 10. The effect of green lands on reducing pollution in region 8 in Shiraz

\begin{tabular}{cccccc}
\hline & Indexes & Frequency & Percentage & Value in Percentage & Accumulative Frequency \\
\hline \multirow{4}{*}{ Valid } & Very much & 7 & $2 / 3$ & $2 / 4$ & $2 / 4$ \\
& Much & 18 & 6 & $5 / 3$ & $7 / 7$ \\
& Moderate & 98 & $32 / 7$ & 33 & $40 / 7$ \\
& Little & 105 & 35 & $35 / 2$ & $75 / 9$ \\
& No effect & 72 & 24 & $24 / 1$ & $100 / 0$ \\
& Total & 300 & $100 / 0$ & $100 / 0$ & \\
\hline
\end{tabular}




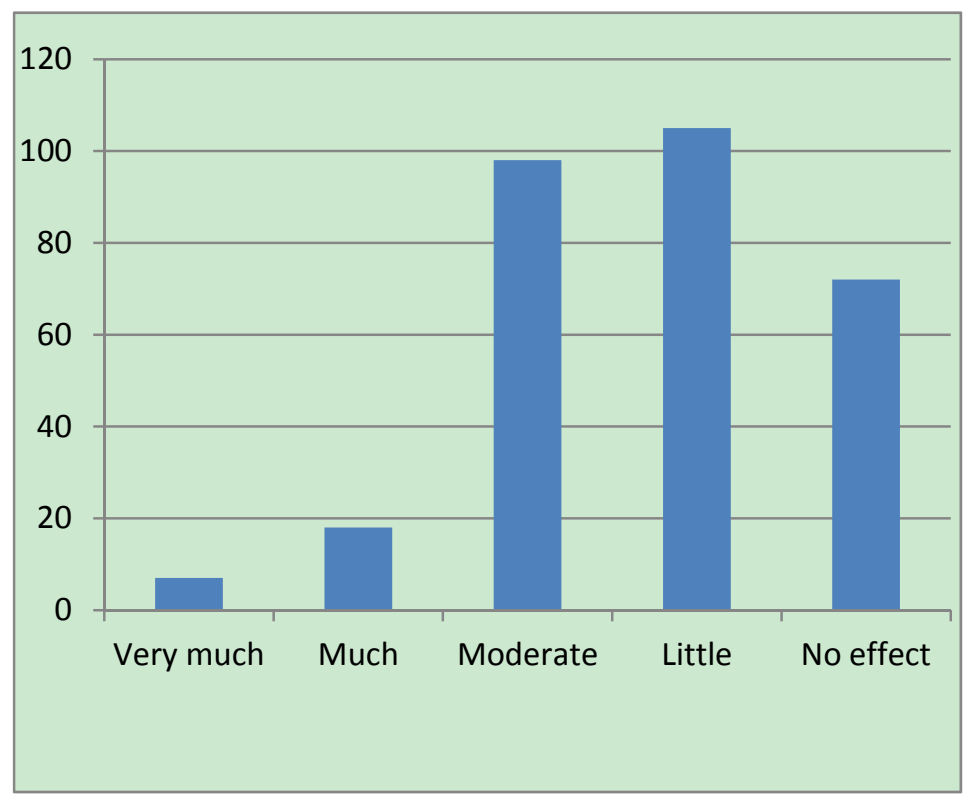

Figure 5. The effect of green lands on reducing pollution in region 8 in Shiraz

Regarding the success of the municipality in providing recreational, health services, etc. in green lands, based on the findings, $0 / 6 \%$ of the respondents selected the option "Very much", $3 / 7 \%$ selected the option "Much", $38 / 6 \%$ "Moderate", 28/7\% "little", and 28/4\% selected "No effect" (Table 11, and Figure 6).

Table 11. The level of the success of the municipality in providing recreational, health services, etc. in green lands

\begin{tabular}{cccccc}
\hline \multicolumn{1}{c}{ Indexes } & Frequency & Percentage & Value in Percentage & Accumulative Frequency \\
\hline \multirow{4}{*}{ Valid } & Very much & 2 & $0 / 6$ & $0 / 6$ & $0 / 6$ \\
& Much & 11 & $3 / 7$ & $2 / 7$ & $3 / 3$ \\
& Moderate & 116 & $38 / 6$ & $38 / 8$ & $42 / 1$ \\
& Little & 86 & $28 / 7$ & $29 / 1$ & $71 / 2$ \\
& No effect & 85 & $28 / 4$ & $28 / 8$ & $100 / 0$ \\
& Total & 300 & $100 / 0$ & $100 / 0$ & \\
\hline
\end{tabular}




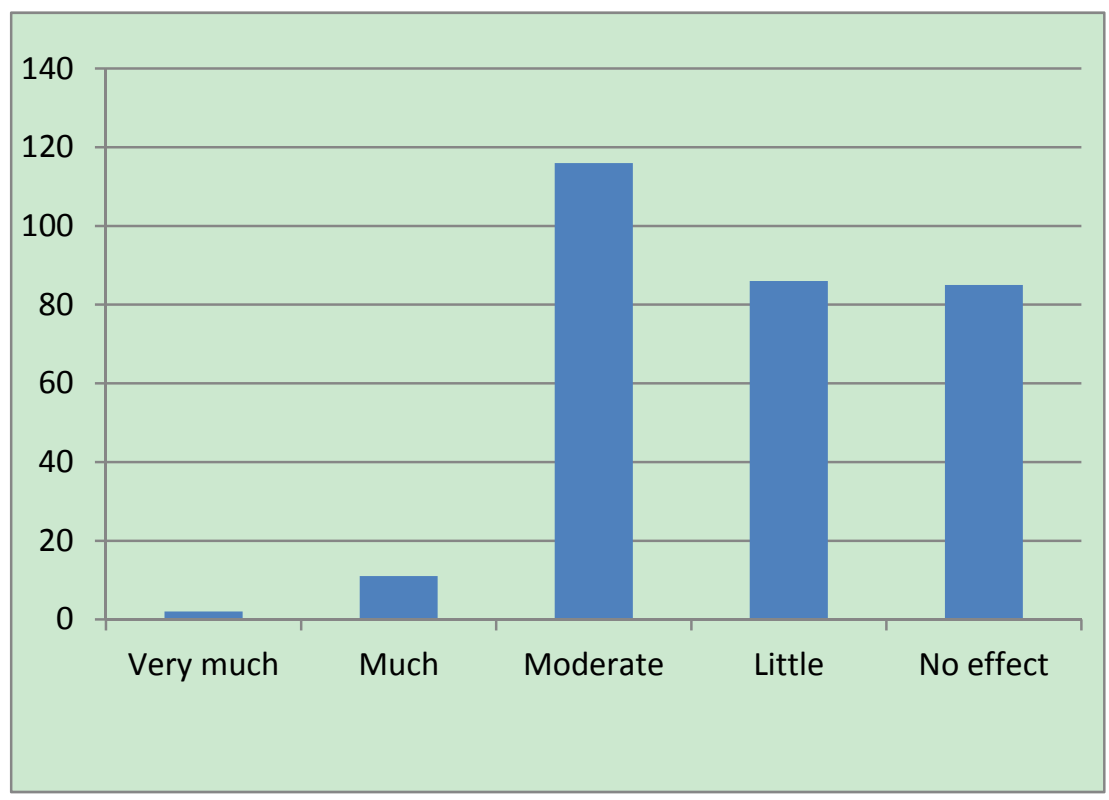

Figure 6. The level of the success of the municipality in providing recreational, health services, etc. in green lands

Regarding access to the nearest green lands, according to the findings, $63 / 7 \%$ of the respondents selected the option "On foot", 17/6\% "Personal vehicle", 1/3\% "Motor vehicle", 1/7\% "Bicycle", and 15/7\% selected the option "Public transport" (Table 12, and Figure 7).

Table 12. Access of the respondents to green lands

\begin{tabular}{cccccc}
\hline & Indexes & Frequency & Percentage & Value in Percentage & Accumulative Frequency \\
\hline \multirow{4}{*}{ Valid } & On foot & 191 & $63 / 7$ & $63 / 9$ & $63 / 9$ \\
& Personal vehicle & 53 & $17 / 6$ & $16 / 8$ & $80 / 7$ \\
& Motor vehicle & 4 & $1 / 3$ & $1 / 4$ & $82 / 1$ \\
& Bicycle & 5 & $1 / 7$ & $1 / 8$ & $83 / 9$ \\
& Public transportation & 47 & $15 / 7$ & $16 / 1$ & $100 / 0$ \\
& Total & 300 & $100 / 0$ & $100 / 0$ & \\
\hline
\end{tabular}




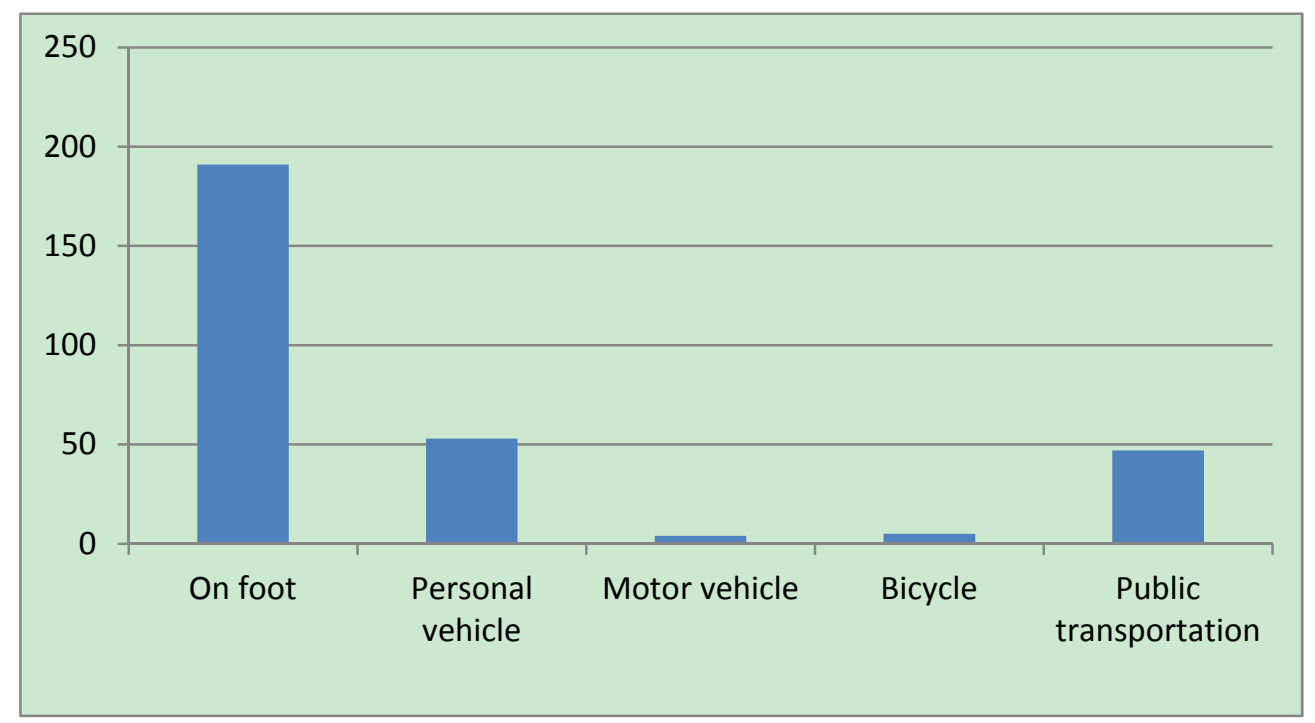

Figure 7. Access of the respondents to green lands

Regarding the suitability and cleanness of parks and green lands in the city or neighborhood, based on findings, $4 / 3 \%$ of the respondents selected the option "Very much", 16/7\% "Much", 28/7\% "Moderate", 45/7\% "little", and 4/6\% selected "No effect" (Table 13, and Figure 8).

Table 13. Evaluation of the suitability and cleanness of parks and green lands in region 8 in Shiraz

\begin{tabular}{cccccc}
\hline & Indexes & Frequency & Percentage & Value in Percentage & Accumulative Frequency \\
\hline \multirow{6}{*}{ Valid } & Very much & 13 & $4 / 3$ & $4 / 3$ & $4 / 3$ \\
& Much & 50 & $16 / 7$ & $15 / 6$ & $19 / 9$ \\
& Moderate & 86 & $28 / 7$ & $29 / 2$ & $49 / 1$ \\
& Little & 137 & $45 / 7$ & $46 / 1$ & $95 / 2$ \\
& No effect & 14 & $4 / 6$ & $4 / 8$ & $100 / 0$ \\
& Total & 300 & $100 / 0$ & $100 / 0$ & \\
\hline
\end{tabular}

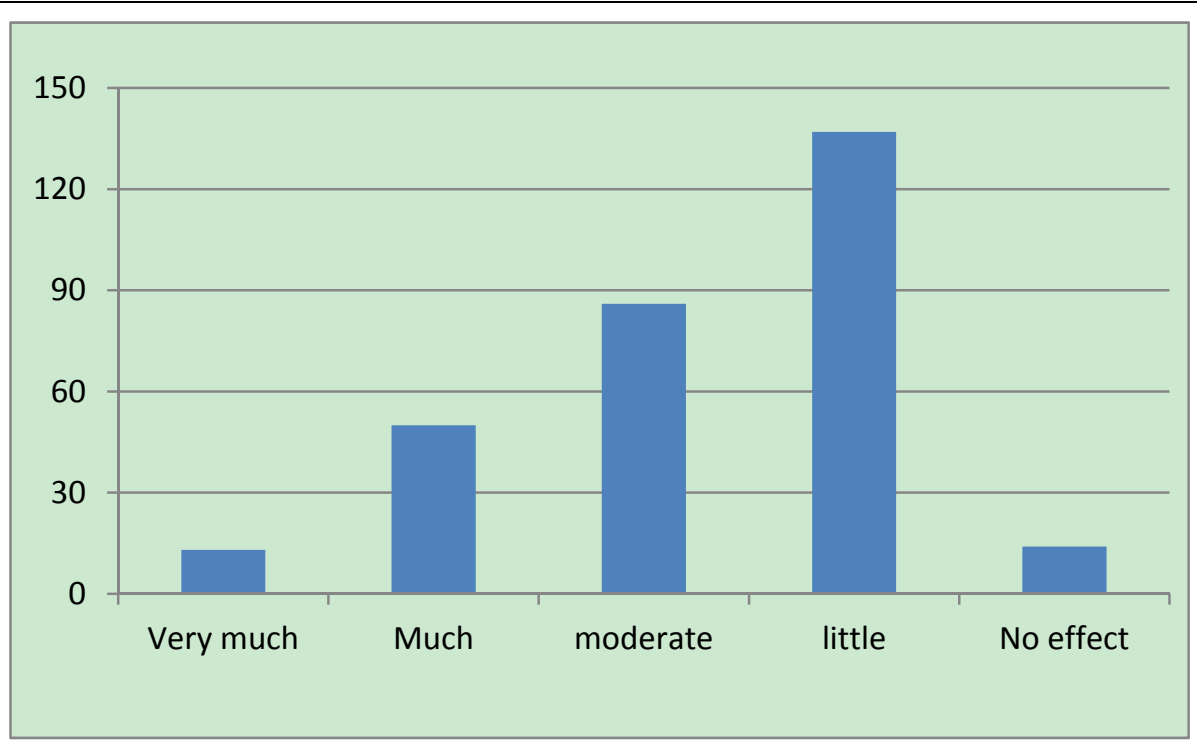

Figure 8. Evaluation of the suitability and cleanness of parks and green lands in region 8 in Shiraz 


\section{Conclusion and Testing the Hypotheses}

The purpose of urban planning is to provide a sustainable living environment for residents of a city because the objective of sustainable development is providing current needs without impairing the ability of future generations to meet their needs. Improving the quality of human life and providing a national framework for the integration and protection of the environment are considered as the most important principles of sustainable development. Many urban problems are related to the lack of coordination between municipal urban organizations in this field and

This can cause problems for the municipality in providing urban services to the citizens like the case in region 8 in Shiraz city. Studying the research findings makes issues clear for planning experts and urban development designers. The results can be an applied guide for planning.

In region 8 in Shiraz, like other urban areas and cities in the country, the proportion of the population to urban green lands becomes increasingly less. As a result of changing the land use of green lands to educational, residential, business, and other uses and not dedicating land to green lands in regions, districts, and neighborhoods, cities will encounter shortage of green lands in a not too distant future.

Based on the research findings, among those who believe that there is a relationship between spatial distribution of green lands and ecological issues in region 8 in Shiraz, those who selected the option "Very much" had a mean of $1 / 56$ and standard deviation of $0 / 6452$, those who chose the option "Much" with a mean of $1 / 6843$ and standard deviation of $0 / 6790$, those who chose the option "Moderate" with a mean of 1/6281 and standard deviation of $0 / 74391$, those who selected the option "Little" had a mean of 1/6987 and standard deviation of $0 / 65473$, and those who selected the option "No effect" had a mean of $1 / 5$ and standard deviation of $0 / 6430$. The significance level of $\mathrm{P}=<0 / 50$ implies that the hypothesis is confirmed. The amount of correlation indicates a strong correlation between the variables. According to the obtained values, this hypothesis is confirmed.

Therefore, it is concluded that there is a significant relationship between the spatial distribution of green lands and ecological issues in region 8 in Shiraz city so that values of significance level in Variance test (ANOVA) is equal to $\mathrm{Sig}=0 / 372$. According to the obtained values, the hypothesis is confirmed.

Pearson correlation indicates a strong positive correlation between the variables of spatial distribution of green lands and ecological problems in region 8 in Shiraz city.

The correlation value generally fluctuates between +1 and -1 . The closer the obtained value to +1 , the stronger the correlation is. The closer the obtained value to -1 , the weaker the correlation is. The correlation of the value 0 is neutral, and the value below zero has inverse correlation. Here, the positive correlation $(R=0 / 054)$ exists between the variables (table 14).

Table 14. The level of correlation in the first hypothesis

\begin{tabular}{ccccccc}
\hline Indexes & Number & Mean & Standard deviation & F value & Level of significance & Correlation \\
\hline Very much & 94 & $1 / 56$ & $0 / 6452$ & & & \\
Much & 120 & $1 / 6843$ & $0 / 6790$ & & & \\
Moderate & 74 & $1 / 6281$ & $0 / 74391$ & $1 / 1550$ & $0 / 372$ & $0 / 054$ \\
Little & 9 & $1 / 6987$ & $0 / 65473$ & & & \\
No effect & 3 & $1 / 5$ & $/ 6430$ & & & \\
Total & 300 & $1 / 61422$ & $0 / 673168$ & & & \\
\hline
\end{tabular}

Table 15.The level of regression of the first hypothesis

\begin{tabular}{ccccccc}
\hline & Model & Sum of squares & df & Mean Squares & F & sig \\
\hline \multirow{4}{*}{1} & Regression & $0 / 284$ & 1 & $0 / 284$ & $0 / 362$ & $0 / 372$ \\
& Residual & $249 / 404$ & 298 & $0 / 784$ & & \\
& Total & $249 / 886$ & 299 & & & \\
\hline
\end{tabular}

The level of significance in the above regression table indicates that the hypothesis is confirmed. 
Based on the research findings, in the second hypothesis among those who believe there is a significant relationship urban management and the spatial distribution of green lands Region 8 in Shiraz, those who selected the option "Very much" had a mean of 1/6567 and standard deviation of $1 / 13560$, those who selected "Much" had a mean of $1 / 39568$ and standard deviation of $0 / 63246$, those who selected "Moderate" had a mean of 1/7123 and standard deviation of $0 / 82659$, those who selected "Little" had a mean of $1 / 6987$ and standard deviation of $0 / 59327$, and those who selected "No effect" had a mean of $1 / 8667$ and standard deviation of $0 / 78182$.

The significance level of $\mathrm{P}=>50 / 0$ implies that the hypothesis is confirmed. In addition, the degree of correlation suggests a strong correlation between variables so that the values of significance level in Variance test (ANOVA) is equal to $\mathrm{Sig}=0 / 16$. Thus, according to the obtained values, the hypothesis is confirmed.

Pearson correlation indicates a strong positive correlation between the variables of urban management and spatial distribution of green lands in region 8 in Shiraz city. There is a positive correlation $(\mathrm{R}=068 / 0)$ among the variables shown in Table 16. In this regard, Table 17, the regression level of the second hypothesis is specified.

Table 16. The degree of correlation in the second hypothesis

\begin{tabular}{ccccccc}
\hline Indexes & Number & Mean & Standard deviation & F Value & Significance level & Correlation \\
\hline Very much & 3 & $1 / 6567$ & $1 / 13560$ & & & \\
Much & 15 & $1 / 39568$ & $0 / 63246$ & & & \\
Moderate & 87 & $1 / 7123$ & $0 / 82659$ & $1 / 677$ & $0 / 16$ & \\
Little & 116 & $1 / 6987$ & $0 / 59327$ & & \\
No effect & 79 & $1 / 8667$ & $0 / 87666$ & & \\
Total & 300 & $1 / 7562$ & $0 / 78182$ & & \\
\hline
\end{tabular}

Table 17. The level of regression in the second hypothesis

\begin{tabular}{ccccccc}
\hline & Model & Sum of squares & df & Mean Squares & F & sig \\
\hline \multirow{4}{*}{1} & Regression & $0 / 480$ & 1 & $0 / 480$ & $0 / 654$ & $0 / 16$ \\
& Residual & $262 / 520$ & 298 & $0 / 826$ & & \\
& Total & $263 / 000$ & 299 & & & \\
\hline
\end{tabular}

The significant level in the above regression table indicates that the hypothesis is confirmed.

Therefore, according to the findings of the research in the field of urban green lands, adopting the following strategies may be useful:

- Paying attention to equal distribution of green lands in region 8 in Shiraz so that all citizens can use the green lands in the shortest time and minimum cost.

- Proper implementation of laws related to the protection of gardens and green lands and preventing their destruction for building houses and residential complexes and changing the land use of urban green lands

- Raising environmental awareness and information of families and the urban population through active education and educational initiatives and plans to protect the existing sustainable green lands in line with providing the conditions for urban sustainability.

- Reducing air pollution through increasing green lands in a balanced distribution and in proportionate to the population of neighborhoods.

\section{References}

Ahmadi, F. (2009). Investigating the Status of Urban land (Green Lands), A Case Study: Nurabad Mamasani City. MS Dissertation. Islamic Azad University, Najaf Abad. 
Almudi, T. (2008). Opportunities and Problems for Participatory Management in the Peixe Lagoon National Perk. Southern Brazil, Thesis for the degree of Master of Natural Resources, University of Manitoba, Canada.

Arianpoor, A. (2000). A Research about Identifying Gardens in Iran and Historic Gardens in Shiraz. Iran History and Culture Publications. Shiraz.

Azani, M. (2004). New Perspectives on Urban Planning Services, Proceedings of the Scientific-Professional Conference of Cities and People. Tabriz University.

Bahram Soltani, K. (2005). An Overview of the History of Landscape Architecture. Environment Journal, (1).

Crane, P., \& Kinzig, A. (2005). Nature in the Metropolis. Science, 308, 1225. $\mathrm{http}: / / \mathrm{dx}$.doi.org/10.1126/science.1114165

De Vries, S., \& Goossen, M. (2002). Modelling recreational visits to forests and nature areas. Urban Forestry \& Urban Greening, 1(1), 5-14. http://dx.doi.org/10.1078/1618-8667-00002

Gülez, S., \& Demirel, O. (2004). An evaluation method for the determination of forest recreation potential: A case study. Countryside Recreation, 12(3/4), 26-34.

Hafeznia, M. R. (2008). An Introduction to the Human Sciences Research Methods. SAMT Publications. Tehran.

Hekmati, J. (2002). Give New Life to Trees on the Streets. Green Lands Journal, (9-10).

Huck, S. W. (2004). Reading statistics and research (4th ed.). Boston: Pearson and AB.

Imani Jorjami, H., Bigdeli, M., \& Hanachi, S. (2002). Sustainable Urban Management, Volume I. The Country's Municipalities Publications, Tehran University.

Jim, C. Y., \& Wendy, Y. C. (2006). Recreation-amenity use and contingent valuation of urban green spaces in Guangzhou, China. Landscape and Urban Planning, 75, 81-96. http://dx.doi.org/10.1016/j.landurbplan.2004.08.008

Kazemi, M., \& Mehdi, S. (2007). Assessment of Urban Development- Concepts, Methods, and Parameters. Noor Courier. Payam Noor University Journal, 5(2).

Keshtkar, A. (2002). Factors Affecting the Aspects of Cities Physical Development (A Case Study: Shiraz City). Master Dissertation. Shiraz University.

Laghaee, H. (2000). Planning and Designing Urban Green Lands. Green Lands Quarterly, II(5 -6).

Lane, M. B., \& Corbett, T. (2005). The Tyranny of Localism: Indigenous Participation in Community-based Environment Management. Journal of Environment policy and Planning, 7(2), 144-159. http://dx.doi.org/10.1080/15239080500338671

Majnoonian, H. (2000). Debates about Parks, Green Lands, and Resorts. Parks and Green Lands publications. Tehran.

Malone, T. F., \& Yohe, G. W. (2002). Knowledge partnership for sustainable, equitable, and stable society. Journal of Knowledge Management, 6(4), 368-378. http://dx.doi.org/10.1108/13673270210440875

Mazini, M. (2000). Areas of Public Life and Private Life. Tehran University Publications.

Mehrmand, S. (2004). Abstracts of the Conference on District Development. Tehran University.

Mizutani, S. (2009). The mechanism of washback on teaching and learning. Unpublished PhD, The University of Auckland, Auckland.

Momeni, M. (2007). Iran Human Geography. Islamic Azad University of Najaf Abad Publications. Isfahan.

Moshkelati, P. (2004). Managing Cities in the World Using Cooperative Patterns. Urban Management and Planning Information Educational Research Quarterly, (60).

Nik-kar, M. (2005). The City Center of Shiraz City over Time. Urban Essays, (12).

Poormohammadi, M. R. (2003). Planning Urban Land Use. SAMT Publications. Tehran.

Processing Consulting Engineers. (2004). Detailed Design in Region 8 in Shiraz. The General Directorate of Urban Planning, Far.

Rosa, E., Eduardo, G., \& Erin, J. (2005). Social adaptation ecotourism in the Lacandon forest. Annals of tourism Research, 32, 610-627. http://dx.doi.org/10.1016/j.annals.2004.08.005 
Saeeidnia, A. (2004). Urban Management, Volume 11, The Country's Municipalities Publications.

Shia, E. (2000). An Introduction to Urban Planning. Science and Technology University Publications. Tehran.

Shia, E. (2003). An Introduction to the Fundamentals of Urban Planning (4th ed.). Science and Technology University Publications. Tehran.

Tissot, B. N. (2005). Integral Marine Ecology: Community-based Fishery Management in Hawaii. Journal of General Evolution, (61), 79-96.

Tsaur, S. H., Lin, Y. C., \& Lin, J. H. (2006). Evaluating ecotourism sustainability from the integrated perspective of resource, community and tourism. Tourism Management, 27(4), 640-653. http://dx.doi.org/10.1016/j.tourman.2005.02.006

Ziari, K. (2006). Planning New Towns. SAMT Publications. Tehran.

\section{Copyrights}

Copyright for this article is retained by the author(s), with first publication rights granted to the journal.

This is an open-access article distributed under the terms and conditions of the Creative Commons Attribution license (http://creativecommons.org/licenses/by/3.0/). 